\title{
Comparative Evaluation of Microroughness created on Titanium Alloy for use in Dental Implants subjected to Two Different Acid Etching Techniques: An in vitro Study
}

\author{
${ }^{1}$ Vishwas Updesh Madaan, ${ }^{2}$ Manjeet Mapara, ${ }^{3}$ Ashvini M Padhye
}

\begin{abstract}
Aim: The aim of this study was to comparatively evaluate the microroughness created on titanium alloy for use in dental implants subjected to two different acid etching techniques.

Materials and methods: Commercially available grade 5 pure titanium plates were machine prepared into 26 plates measuring $3 \times 1 \mathrm{~cm} \times 5 \mathrm{~mm}$ for acid etching with hydrofluoric acid (HF) and dual acid etching technique using sulfuric acid $\left(\mathrm{H}_{2} \mathrm{SO}_{4}\right)$ followed by hydrochloric acid $(\mathrm{HCl})$. Twenty-five plates were divided into four groups based on the duration and sequence of acid etching. Upon completion of the acid etching procedure, the titanium plates were assessed for their surface characteristics by a surface profilometer. The average roughness parameters values $\mathrm{Ra}, \mathrm{Rq}, \mathrm{Rz}$ obtained for each titanium plate were compared against each other and with unetched titanium plate.
\end{abstract}

Results: The average roughness value Ra obtained was 0.480 $\mu \mathrm{m}$ for untreated surface and $3.65 \mu \mathrm{m}$ maximum for the titanium plate etched for 72 hours in $\mathrm{H}_{2} \mathrm{SO}_{4}$ and 48 hours in $\mathrm{HCl}$, which is about seven times the value of surface roughness on the unetched plates. The roughness values obtained after acid etching with $\mathrm{HF}$ for any duration were nonsignificant compared with the unetched plates.

Conclusion: The dual acid etching technique seems to be a simple method to develop a titanium implant surface, though evaluation of the biological response to this surface is necessary.

Clinical significance: The present study showed that by optimizing the parameters of acid etching, a rough titanium surface can be obtained similar to the various implant surfaces available commercially.

Keywords: Acid etching, Dental implant, Profilometer, Surface topography.

How to cite this article: Madaan VU, Mapara M, Padhye AM. Comparative Evaluation of Microroughness created on Titanium Alloy for use in Dental Implants subjected to Two Different Acid Etching Techniques: An in vitro Study. J Contemp Dent 2016;6(1):1-8.

Source of support: Nil

Conflict of interest: None

${ }^{1}$ Postgraduate Student, ${ }^{2}$ Senior Lecturer, ${ }^{3}$ Professor and Head

${ }^{1-3}$ Department of Periodontics, MGM Dental College and Hospital, Navi Mumbai, Maharashtra, India

Corresponding Author: Vishwas Updesh Madaan Postgraduate Student, Department of Periodontics, MGM Dental College and Hospital, Navi Mumbai, Maharashtra, India, Phone: +919702204996, e-mail: drvishwasmadaan@yahoo.com

\section{INTRODUCTION}

Osseointegration consists of a series of bone modeling and remodeling processes. It has actually been defined as the direct structural and functional connection between living bone and the surface of a load-bearing artificial implant. The success of osseointegration depends on the quality, distribution, and amount of bone present at the site of the dental implant. ${ }^{1}$ The nature of the implant surface has been recognized to be a critical factor for osseointegration. The most important surface properties are topography, chemistry, surface charge, and wettability. ${ }^{2}$ Endosseous dental implants are available with various surface characteristics ranging from relatively smooth-machine surfaces to more roughened surfaces by coating, blasting by various methods, by acid treatments or by a combination of the treatments. ${ }^{3}$ Response of the tissues to the implant is largely controlled by the nature and texture of the surface of the implant. ${ }^{4}$ Some of these have the ability to enhance and direct the growth of bone and achieve osseointegration when implanted in osseous sites.

Altering the surface topography of an implant can greatly improve its stability. ${ }^{5}$ Based on the scale of the features, the surface roughness of implants can be divided into macro-, micro-, and nano-sized topologies. ${ }^{6}$ Surface irregularities of an implant can be designed by making porous and/or by coating the implant surface with other suitable materials to increase bone-implant contact, as the anatomic surface of bone cannot be controlled. ${ }^{7}$

Surface irregularities can be produced through ablative/subtractive procedures or additive procedures.

Ablative procedures

- Grit blasting

- Acid etching

- Shot/Laser peening
Additive procedures

- Plasma spraying

- Electrophoretic deposition

- Sputter deposition

- Sol Gel coating

- Anodizing

- Pulsed laser deposition

- Biomimetic precipitation 
Modifications of the implant surface features an increase in retention between the implant and the bone by enlarging the contact surface, increasing the biomechanical interlocking between implant and bone, and by enhancing osteoblast activity with quicker formation of bone at the interface. ${ }^{8}$

Acid etching appears to greatly enhance the potential for osseointegration especially in the earliest stages of periimplant bone healing. Also with this technique, there is no need for any external agent that contaminates the implant surface. Acid treatment produces a clean, highly detailed surface texture and lacks entrapped surface material and impurities. This has been reported to have a positive effect on the biologic response in terms of bone apposition, a higher percentage of direct bone to implant contact, and strong implant anchorage. ${ }^{9}$ Studies demonstrated ${ }^{10-13}$ that optimal surface roughness of particles of $75 \mu \mathrm{m}$ made surface more resistant to torque and greater bone to metal contact than small $(25 \mu \mathrm{m})$ or coarse $(250 \mu \mathrm{m})$ particles. Also, precise acid selection and the sequence of processing played the main role in preparation of the rough titanium surface. The surfaces were poorer if they were etched with hydrochloric acid $(\mathrm{HCl})$ than with sulfuric acid $\left(\mathrm{H}_{2} \mathrm{SO}_{4}\right)$. The sequence of $\mathrm{H}_{2} \mathrm{SO}_{4}$ followed by $\mathrm{HCl}$ showed the best results, and as the acid-etched texture is contiguous with the porous coating, there is no possibility of debonding or dissolution, thus avoiding concerns with third body wear particles or long-term fixation..$^{10}$

\section{Aim}

The aim of this study was to comparatively evaluate the microroughness created on titanium alloy for use in dental implants subjected to two different acid etching techniques.

\section{Objectives}

The objectives of this study are as follows:

- To evaluate the suitability and handling characteristics of hydrofluoric acid for obtaining a titanium surface suitable for use in dental implants.

- To evaluate the suitability of application of dual acid etching technique with $\mathrm{H}_{2} \mathrm{SO}_{4}$ and $\mathrm{HCl}$ at varying time intervals for obtaining a titanium surface suitable for use in dental implants.

- To identify the technique that yields minimum and maximum surface roughness as measured by a surface profilometer.

- To evaluate and compare the surface characteristics of etched and unetched titanium plates with the help of a surface profilometer.
- To develop a technique of acid etching using a combination of two acids that yields a surface roughness similar to the commercially available dental implants.

\section{MATERIALS AND METHODS}

\section{Acid Etching Procedure}

Commercially available pure titanium grade 5 sheet was machine prepared to form 26 plates measuring $3 \times 1 \mathrm{~cm}$ $\times 5 \mathrm{~mm}$ each. One plate $\mathrm{T}_{0}$ was left unetched; the rest of 25 plates that were to be subjected to acid etching were divided into four groups (group I- $\mathrm{H}_{2} \mathrm{SO}_{4} 72$ hours, group II $-\mathrm{H}_{2} \mathrm{SO}_{4} 66$ hours, group III $-\mathrm{H}_{2} \mathrm{SO}_{4} 88$ hours, group IV - HF) based on the duration of exposure to $\mathrm{H}_{2} \mathrm{SO}_{4}$ and numbered from $\mathrm{T} 1$ to $\mathrm{T} 13$ based on the duration of exposure to $\mathrm{HCl}$, which varied from 18 to 48 hours as follows:

\section{$\mathrm{T}_{0}$ : Unetched plates}

$\left.\begin{array}{l}\text { T1: } \mathrm{H}_{2} \mathrm{SO}_{4} 72 \text { hours }-\mathrm{HCl} 18 \text { hours } \\ \text { T2: } \mathrm{H}_{2} \mathrm{SO}_{4} 72 \text { hours }-\mathrm{HCl} 24 \text { hours } \\ \text { T3: } \mathrm{H}_{2} \mathrm{SO}_{4} 72 \text { hours }-\mathrm{HCl} 30 \text { hours } \\ \text { T4: } \mathrm{H}_{2} \mathrm{SO}_{4} 72 \text { hours }-\mathrm{HCl} 36 \text { hours } \\ \text { T5: } \mathrm{H}_{2} \mathrm{SO}_{4} 72 \text { hours }-\mathrm{HCl} 48 \text { hours }\end{array}\right\}$ Group I

$\left.\begin{array}{l}\text { T10: } \mathrm{H}_{2} \mathrm{SO}_{4} 88 \text { hours }-\mathrm{HCl} 24 \text { hours } \\ \text { T11: } \mathrm{H}_{2} \mathrm{SO}_{4} 88 \text { hours }-\mathrm{HCl} 30 \text { hours } \\ \text { T12: } \mathrm{H}_{2} \mathrm{SO}_{4} 88 \text { hours }-\mathrm{HCl} 36 \text { hours } \\ \text { T13: } \mathrm{H}_{2} \mathrm{SO}_{4} 88 \text { hours }-\mathrm{HCl} 48 \text { hours }\end{array}\right\}$ Group III

Based on the duration of exposure to HF acid $(40 \%)$, the titanium plates were numbered from T14 to T25 as follows:

T14: HF 15 seconds

T15: HF 30 seconds

T16: HF 45 seconds

T17: HF 60 seconds

T18: HF 75 seconds

T19: HF 90 seconds

T20: HF 105 seconds

T21: HF 120 seconds

T22: HF 135 seconds

T23: HF 150 seconds

T24: HF 165 seconds

T25: HF 180 seconds

Group IV

A groove was prepared on one side of every plate with a straight fissure diamond bur and air-rotor to identify the side on which the roughness measurement will be made after acid etching. All procedures of acid etching were performed in a certified fume hood* available at MGM Central Research Laboratory.

*LabGuard technologies Fume Hood Maxima 


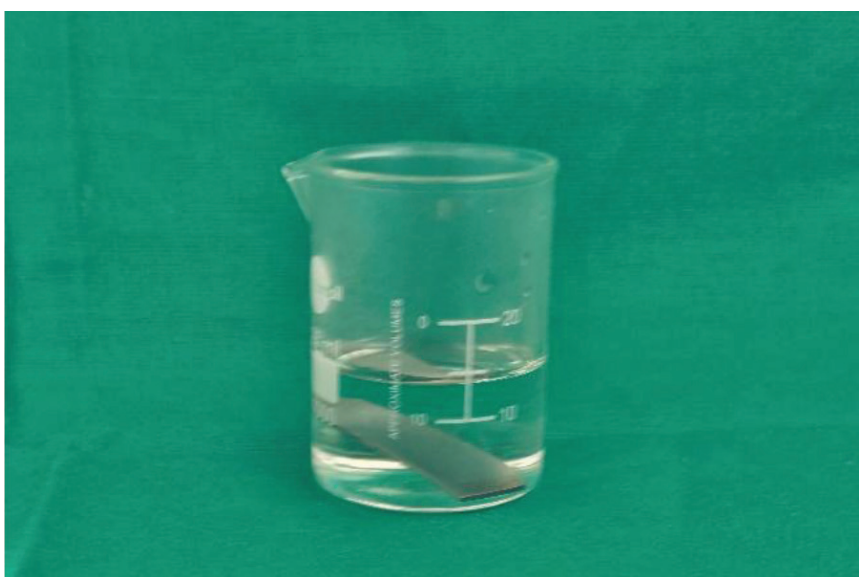

Fig. 1: Acid etching of titanium plate

The plates numbered T1-T13 were kept angulated in $25 \mathrm{ml}$ borosilicate glass beakers such that only top and bottom edge of the plate touched the beaker, and the acid $\mathrm{H}_{2} \mathrm{SO}_{4}(98 \%$ ) (Fig. 1) was poured along the side of the beaker until the top edge of the titanium plate was completely immersed in the acid. These plates were then divided into three groups. Group 1 was exposed to $\mathrm{H}_{2} \mathrm{SO}_{4}$ for 72 hours, group 2 was exposed to $\mathrm{H}_{2} \mathrm{SO}_{4}$ for 66 hours, and group 3 was exposed to $\mathrm{H}_{2} \mathrm{SO}_{4}$ for 88 hours.

The beakers were kept untouched till the specified time as cited previously for each specimen. All T1-T13 plates were removed with tweezers washed in an ultrasonic bath with distilled water for 1 minute and kept in another beaker to be filled with $\mathrm{HCl}$ (35-38\%). Plates in group 1 were subjected to $\mathrm{HCl}$ for 18, 24, 30, 36, and 48 hours, and plates in groups 2 and 3 were subjected to $\mathrm{HCl}$ for 24, 30, 36 and 48 hours.

The plates numbered T14-T25 were immersed in the previously filled teflon beaker containing HF (40\%) for 15 to 180 seconds at every 15 -second intervals.

Upon completion of the acid etching procedure, the titanium plates were held from the sides with a tweezer and rinsed with distilled water, dried and kept in air-tight plastic bags until further evaluation.

\section{Topographical Evaluation of Titanium Plates}

All 26 titanium plates were assessed for their surface characteristics by a Mitutoyo 178-561-02A Surftest SJ-210 surface profilometer** calibrated (Fig. 2) according to the manufacturer's instructions.

The marked surface of the plates was kept facing upwards on a flat surface parallel to the floor. The recording head of the surface profilometer was kept at a distance of $5 \mathrm{~mm}$ from the side edge and $1 \mathrm{~cm}$ from the top of the plate to record the roughness measurements in a linear distance of $5 \mathrm{~mm}$ (Fig. 3).

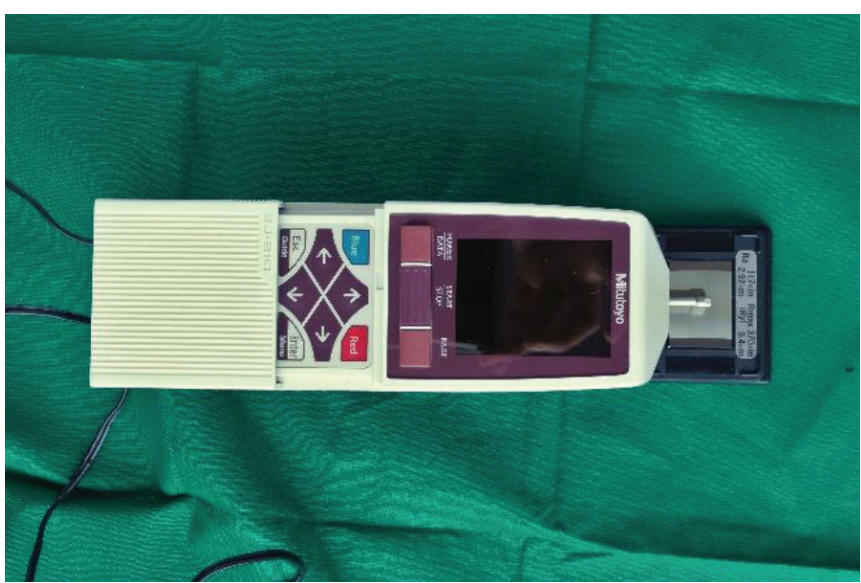

Fig. 2: Mitutoyo 178-561-02A Surftest SJ-210 surface profilometer

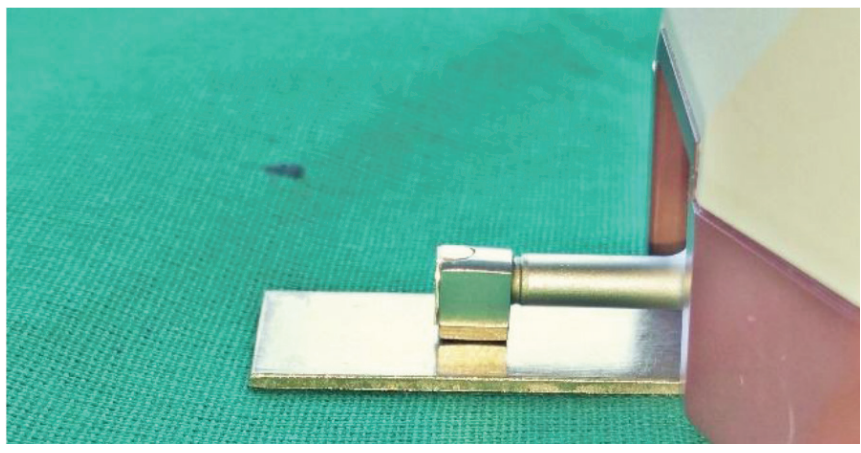

Fig. 3: Measuring the surface roughness of titanium plate using surface profilometer

The following variables of roughness were obtained for each plate:

- Roughness parameters (DIN EN ISO 4287:1998)

- Ra-Arithmetic mean surface roughness: Arithmetical mean of the sums of all profile values in a given linear sample.

- $\mathrm{Rq}$ - Root mean square of the Ra values; it is a value characteristic of a continuously varying quantity.

- $\mathrm{Rz}$ - Average distance between the highest peak and lowest valley in each sampling length.

Three measurements were performed for each specimen according to ISO 4287: 1997.

The arithmetic mean deviation of the profile ( $\mathrm{Ra}$ ) and the maximum height $(\mathrm{Rz})$ were measured with a cut-off value of $0.8 \mathrm{~mm}$, measurement length of $5 \mathrm{~mm}$, measurement speed of $0.6 \mathrm{~mm} / \mathrm{s}$, and a Gaussian filter.

\section{Statistical Analyses}

Statistical analyses were performed using the Statistical Packages for the Social Science (SPSS)/ PC+ version 17.1 program (SPSS Inc., Chicago, Illinois, USA). The means and standard deviations of data were calculated. ShapiroWilk's test was done to find distribution of data. One-way analysis of variance (ANOVA) with Duncan's multiple comparisons test was performed to evaluate differences

**Mitutoyo 178-561-02A Surftest SJ-210 Surface Roughness Tester 
between groups. Values of $\mathrm{p}$ less than 0.05 were considered statistically significant.

\section{RESULTS}

The average roughness values $\mathrm{Ra}, \mathrm{Rq}, \mathrm{Rz}$ evaluated, for untreated and acid etched samples, are reported in Tables 1 to 3 respectively.

The characterization of the implant surfaces carried out by roughness profilometer showed different aspects in the topographies of the surfaces of titanium plates due to the different duration and combination of acids used in the etching process.

From Table 1, it is clear that the roughness value of titanium surfaces increased after various surface treatments. From the experiment, the average roughness value Ra obtained is $0.480 \mu \mathrm{m}$ for untreated surface and $3.65 \mu \mathrm{m}$ maximum for the $\mathrm{T} 5$ titanium plate after 72 hours of $\mathrm{H}_{2} \mathrm{SO}_{4}$ and 48 hours of $\mathrm{HCl}$ etching, which is about seven times the base value of the unetched surface.

Test for normality of distribution of data was performed using Shapiro-Wilk's test. The data were found

Table 1: Ra values for T1-T13

\begin{tabular}{llllll}
\hline Unetched & T0 & 0.418 & 0.528 & 0.484 & 0.480 \\
\hline Groups & Groups & Ra-1 & Ra-2 & Ra-3 & Average \\
\hline $72 / 18$ & T1 & 1.08 & 1.291 & 0.927 & 1.10 \\
$72 / 24$ & T2 & 0.847 & 0.843 & 0.843 & 0.84 \\
$72 / 30$ & T3 & 3.328 & 3.244 & 2.918 & 3.16 \\
$72 / 36$ & T4 & 0.708 & 0.721 & 0.758 & 0.73 \\
$72 / 48$ & T5 & 3.732 & 3.729 & 3.489 & 3.65 \\
$66 / 24$ & T6 & 1.338 & 0.93 & 0.741 & 1.00 \\
$66 / 30$ & T7 & 0.632 & 0.794 & 0.74 & 0.72 \\
$66 / 36$ & T8 & 2.093 & 1.387 & 0.971 & 1.48 \\
$66 / 48$ & T9 & 0.813 & 1.15 & 0.762 & 0.91 \\
$88 / 24$ & T10 & 0.915 & 0.903 & 0.809 & 0.88 \\
$88 / 30$ & T11 & 1.764 & 1.845 & 1.767 & 1.79 \\
$88 / 36$ & T12 & 2.743 & 2.158 & 2.874 & 2.59 \\
$88 / 48$ & T13 & 3.093 & 3.16 & 3.181 & 3.14 \\
\hline
\end{tabular}

Table 2: $\mathrm{Rq}$ values for $\mathrm{T} 1-\mathrm{T} 13$

\begin{tabular}{llllll}
\hline Unetched & T0 & 0.609 & 0.622 & 0.601 & 0.612 \\
\hline Groups & Groups & $R q-1$ & $R q-2$ & $R q-3$ & Average \\
\hline $72 / 18$ & T1 & 1.361 & 1.648 & 1.162 & 1.39 \\
$72 / 24$ & T2 & 1.063 & 1.045 & 1.055 & 1.05 \\
$72 / 30$ & T3 & 3.966 & 3.831 & 3.908 & 3.90 \\
$72 / 36$ & T4 & 0.896 & 0.911 & 0.973 & 0.93 \\
$72 / 48$ & T5 & 4.407 & 4.954 & 5.312 & 4.89 \\
$66 / 24$ & T6 & 1.683 & 1.169 & 0.93 & 1.26 \\
$66 / 30$ & T7 & 0.802 & 0.999 & 0.93 & 0.91 \\
$66 / 36$ & T8 & 2.611 & 1.735 & 1.213 & 1.85 \\
$66 / 48$ & T9 & 1.012 & 1.438 & 0.96 & 1.14 \\
$88 / 24$ & T10 & 1.137 & 1.117 & 0.994 & 1.08 \\
$88 / 30$ & T11 & 2.278 & 2.355 & 2.225 & 2.29 \\
$88 / 36$ & T12 & 3.424 & 2.742 & 3.703 & 3.29 \\
$88 / 48$ & T13 & 3.882 & 3.81 & 3.977 & 3.89 \\
\hline
\end{tabular}

Table 3: $\mathrm{Rz}$ values for $\mathrm{T} 1-\mathrm{T} 13$

\begin{tabular}{llllll}
\hline Unetched & T0 & 3.336 & 3.342 & 3.426 & 3.394 \\
\hline Groups & Groups & Rz-1 & $R z-2$ & $R z-3$ & Average \\
\hline $72 / 18$ & T1 & 7.851 & 9.471 & 6.849 & 8.06 \\
$72 / 24$ & T2 & 6.278 & 6.255 & 6.321 & 6.28 \\
$72 / 30$ & T3 & 18.092 & 18.109 & 24.927 & 20.38 \\
$72 / 36$ & T4 & 5.523 & 5.586 & 6.293 & 5.80 \\
$72 / 48$ & T5 & 23.711 & 24 & 26.91 & 24.87 \\
$66 / 24$ & T6 & 10.038 & 5.996 & 5.426 & 7.15 \\
$66 / 30$ & T7 & 5.319 & 5.818 & 5.519 & 5.55 \\
$66 / 36$ & T8 & 13.218 & 9.091 & 7.447 & 9.92 \\
$66 / 48$ & T9 & 6.151 & 7.578 & 5.982 & 6.57 \\
$88 / 24$ & T10 & 6.305 & 6.107 & 5.396 & 5.94 \\
$88 / 30$ & T11 & 11.894 & 14.267 & 12.673 & 12.94 \\
$88 / 36$ & T12 & 19.238 & 16.784 & 20.011 & 18.68 \\
$88 / 48$ & T13 & 19.875 & 19.813 & 20.305 & 20.00 \\
\hline
\end{tabular}

Table 4: Descriptive statistics

\begin{tabular}{|c|c|c|c|c|c|c|}
\hline & \multicolumn{2}{|r|}{$R a$} & \multicolumn{2}{|c|}{$R q$} & \multicolumn{2}{|r|}{$R z$} \\
\hline & Mean & $\begin{array}{l}\text { Standard } \\
\text { deviation }\end{array}$ & Mean & $\begin{array}{l}\text { Standard } \\
\text { deviation }\end{array}$ & Mean & $\begin{array}{l}\text { Standard } \\
\text { deviation }\end{array}$ \\
\hline T1 & 1.10 & 0.18 & 1.39 & 0.24 & 8.06 & 1.32 \\
\hline T2 & 0.84 & 0.00 & 1.05 & 0.01 & 6.28 & 0.03 \\
\hline T3 & 3.16 & 0.22 & 3.90 & 0.07 & 20.38 & 3.94 \\
\hline T4 & 0.73 & 0.03 & 0.93 & 0.04 & 5.80 & 0.43 \\
\hline T5 & 3.65 & 0.14 & 4.89 & 0.46 & 24.87 & 1.77 \\
\hline T6 & 1.00 & 0.31 & 1.26 & 0.38 & 7.15 & 2.51 \\
\hline T7 & 0.72 & 0.08 & .91 & 0.10 & 5.55 & 0.25 \\
\hline T8 & 1.48 & 0.57 & 1.85 & 0.71 & 9.92 & 2.97 \\
\hline T9 & 0.91 & 0.21 & 1.14 & 0.26 & 6.57 & 0.88 \\
\hline T10 & 0.88 & 0.06 & 1.08 & 0.08 & 5.94 & 0.48 \\
\hline T11 & 1.79 & 0.05 & 2.29 & 0.07 & 12.94 & 1.21 \\
\hline T12 & 2.59 & 0.38 & 3.29 & 0.49 & 18.68 & 1.68 \\
\hline T13 & 3.14 & 0.05 & 3.89 & 0.08 & 20.00 & 0.27 \\
\hline
\end{tabular}

to be normally distributed; hence, we used ANOVA to compare in between the groups (Table 4).

Graph 1 shows the changes in roughness parameters in group 1 when $\mathrm{H}_{2} \mathrm{SO}_{4}$ was kept constant at 72 hours and duration in $\mathrm{HCl}$ was varied from 18, 24, 30, 36, and 48 hours. Analyzing the trend of Ra values, one can appreciate that the average depth of the grooves of the new roughened microsurface increased sharply when plates were etched for 36, and 48 hours in $\mathrm{HCl}$.

Graph 2 shows the roughness parameters in group 2 when $\mathrm{H}_{2} \mathrm{SO}_{4}$ was kept constant at 66 hours and duration in $\mathrm{HCl}$ varied from $24,30,36$ and 48 hours. The roughness values in this group were lesser than group I, indicating that $\mathrm{H}_{2} \mathrm{SO}_{4}$ exposure at 66 hours was weaker and less significant for creating microroughness on the titanium surface.

Graph 3 shows the roughness values in group III when $\mathrm{H}_{2} \mathrm{SO}_{4}$ was kept at 88 hours and $\mathrm{HCl}$ was varied from 24, 30, 36, and 48 hours. Analyzing the trend of roughness parameter in this group indicated that as the 


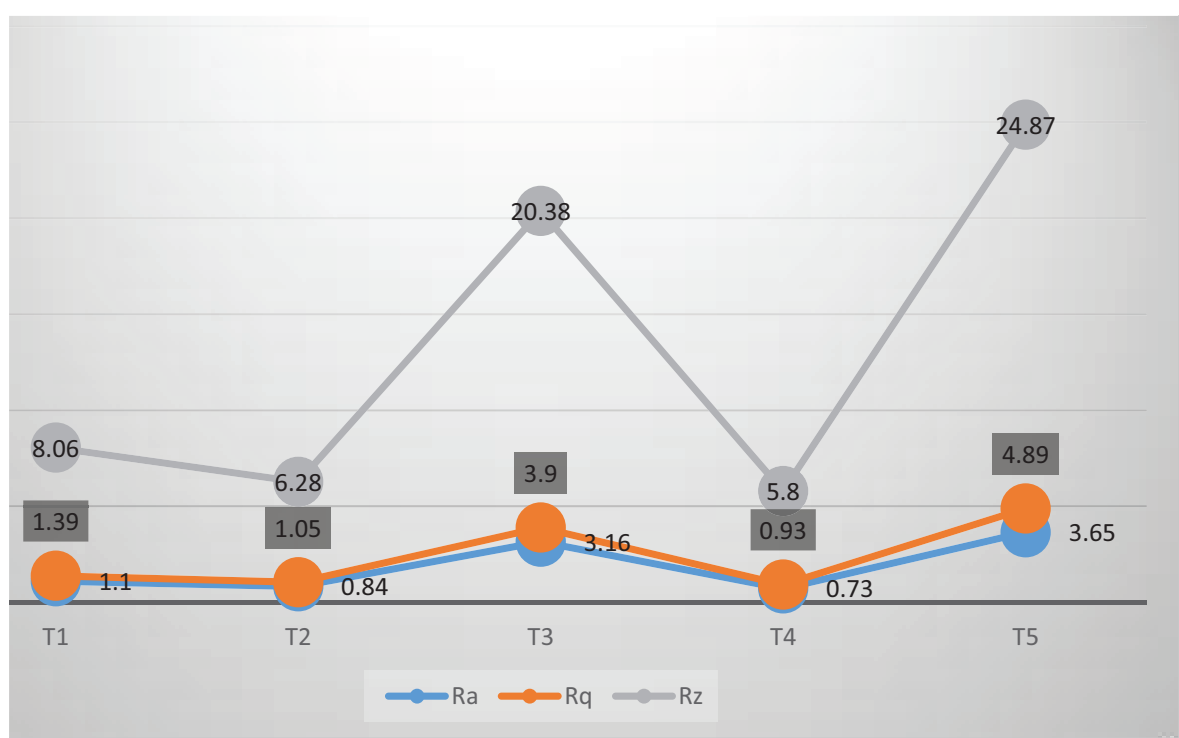

Graph 1: $\mathrm{H}_{2} \mathrm{SO}_{4}-72$ hours

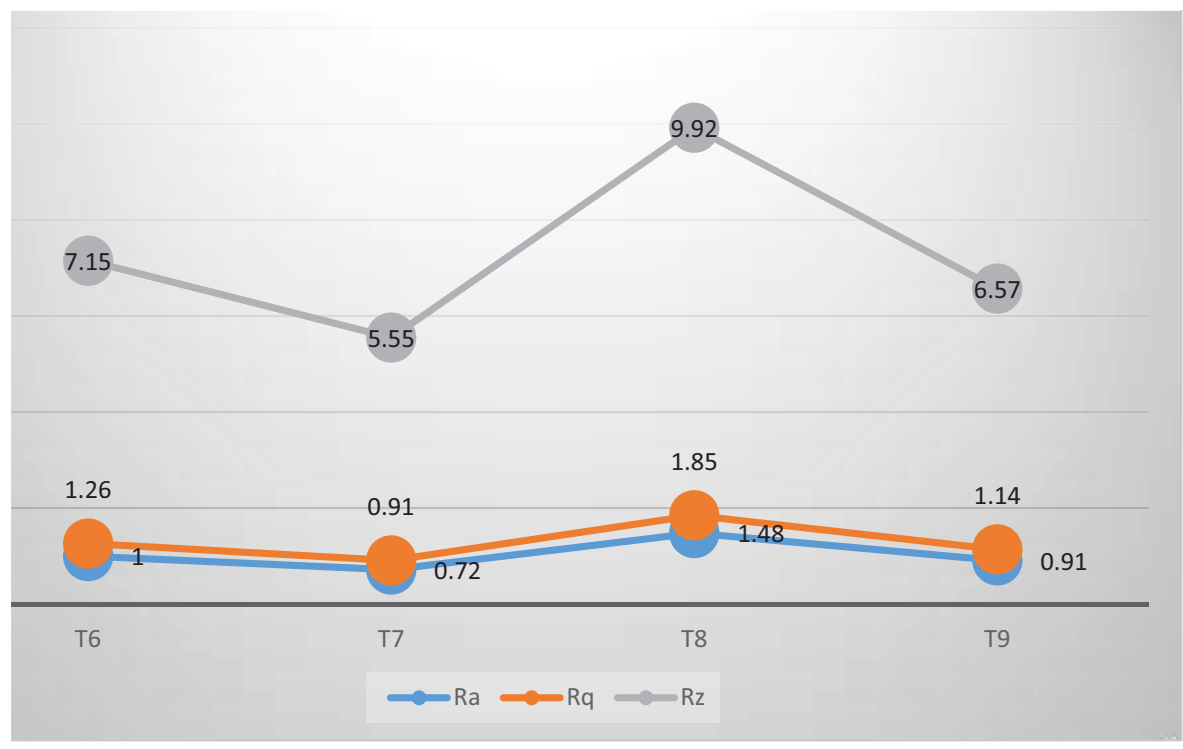

Graph 2: $\mathrm{H}_{2} \mathrm{SO}_{4}-66$ hours

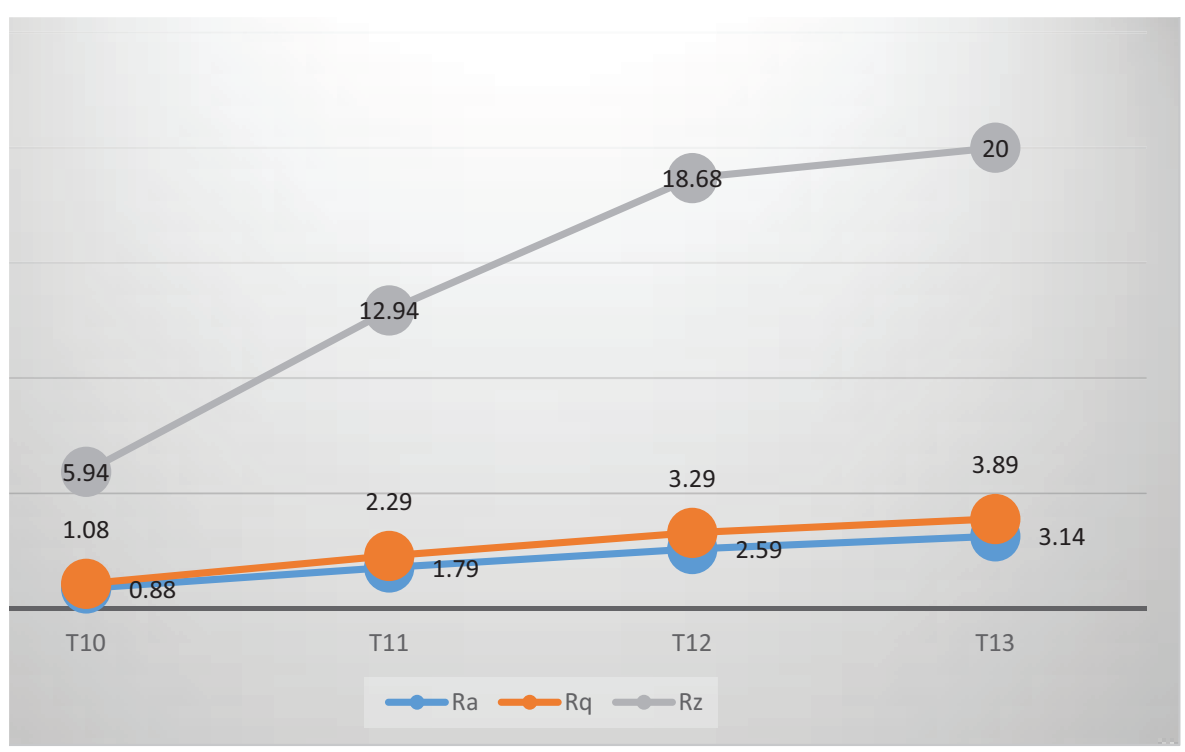

Graph 3: $\mathrm{H}_{2} \mathrm{SO}_{4}-88$ hours 
Table 5: Ra, Rq, Rz values for T14-T25

\begin{tabular}{lllll}
\hline Unetched & T0 & 0.418 & 0.528 & 0.484 \\
\hline Groups & Groups & $R a$ & $R q$ & $R z$ \\
\hline 15 & T14 & 0.565 & 0.852 & 3.566 \\
30 & T15 & 0.544 & 0.843 & 3.458 \\
45 & T16 & 0.526 & 1.115 & 3.918 \\
60 & T17 & 0.548 & 0.959 & 3.758 \\
75 & T18 & 0.432 & 0.729 & 3.489 \\
90 & T19 & 0.378 & 0.930 & 2.741 \\
105 & T20 & 0.342 & 0.794 & 2.074 \\
120 & T21 & 0.553 & 1.387 & 3.971 \\
135 & T22 & 0.513 & 1.15 & 3.762 \\
150 & T23 & 0.415 & 0.903 & 2.908 \\
165 & T24 & 0.364 & 0.845 & 2.967 \\
180 & T25 & 0.343 & 0.758 & 2.874 \\
\hline
\end{tabular}

Table 6: Ra comparison with initial value $=0.48$

\begin{tabular}{|c|c|c|c|c|c|}
\hline & \multicolumn{4}{|c|}{ Test value $=0.48$} & \multirow[b]{2}{*}{ Interpretation } \\
\hline & $t$ & $d f$ & $p$ & Mean difference & \\
\hline T1 & 5.869 & 2 & 0.028 & 0.61933 & $\mathrm{~S}$ \\
\hline T2 & 273.250 & 2 & 0.00001 & 0.36433 & S \\
\hline T3 & 21.460 & 2 & 0.002 & 2.68333 & S \\
\hline T4 & 16.625 & 2 & 0.004 & 0.24900 & S \\
\hline T5 & 39.377 & 2 & 0.001 & 3.17000 & S \\
\hline T6 & 2.969 & 2 & 0.097 & 0.52300 & NS \\
\hline T7 & 5.082 & 2 & 0.037 & 0.24200 & $S$ \\
\hline T8 & 3.065 & 2 & 0.092 & 1.00367 & NS \\
\hline T9 & 3.519 & 2 & 0.072 & 0.42833 & NS \\
\hline T10 & 11.806 & 2 & 0.007 & 0.39567 & $S$ \\
\hline T11 & 49.483 & 2 & 0.00041 & 1.31200 & S \\
\hline T12 & 9.594 & 2 & 0.011 & 2.11167 & S \\
\hline T13 & 100.420 & 2 & 0.00010 & 2.66467 & S \\
\hline
\end{tabular}

S: Significant; NS: Not significant

Interpretation criteria:

- $p$ value less than that of 0.05 indicates significance of difference between the group mean and initial value, i.e., 0.48

- Lower the $p$ value, more is the significance

duration of exposure was increased with $\mathrm{HCl}$, the roughness increased considerably.

Table 5 summarizes the $\mathrm{Ra}, \mathrm{Rq}$, and $\mathrm{Rz}$ values of titanium plates numbered T14-T25, which were subjected to HF acid etching. These plates did not show any significant increase in the roughness values compared with the unetched titanium plates and dual etched plates.

Plates $\mathrm{T}_{6}, \mathrm{~T}_{8}$, and $\mathrm{T}_{9}$ did not show any significant change in roughness parameter Ra (Table 1) when compared with unetched plates. All three being from group II indicating that exposure of titanium for 66 hours in $\mathrm{H}_{2} \mathrm{SO}_{4}$ did not yield a significantly rough surface (Table 6).

\section{DISCUSSION}

Osseointegration consists of a series of bone modeling and remodeling processes, which causes direct structural and functional connection between living bone and the surface of a load-bearing artificial implant. Barier et $\mathrm{al}^{14}$ discussed the features that play the most significant role in early osseointegration and immobilization of the implant in the tissue bed. Texture, charge, and chemistry of the surface as well as cleanliness were considered to be the most important requirements for the implant material. ${ }^{12}$ Predecki et a ${ }^{16}$ observed rapid bone growth and good mechanical adherence with an implant that had an irregular surface. Based on the fact that the quality of osseointegration is directly related to the topography of dental implant surfaces, many techniques related to the modifications carried out on implant surfaces have been tested during the last 30 years. These tests take into account the principle that the topography of a rough surface presents an area for bone anchorage that is much larger than a smooth surface does. ${ }^{14}$ Characteristics of titanium implant surfaces have been modified by additive methods (e.g., titanium plasma spray) or subtractive methods (e.g., blasting, acid etching) to increase the surface area and to alter its microtopography or texture. ${ }^{15}$

Buser et $\mathrm{a}^{19}$ showed that implants with sandblasted and acid-etched surfaces had higher bone to implant contact percentages than implants with titanium plasma sprayed surfaces. However, it should be emphasized that this titanium surface was gained using two methods of processing-sandblasting and acid etching.

A new surface treatment that produces a microroughness similar to the blasted/etched surface but uses only special dual acid etching without grit blasting has been developed. The purpose of this dual etching is to produce a micro-rough surface that provides rapid osseointegration, while maintaining the long-term success associated with a machined implant surface. ${ }^{17}$

In the present study, two methods of surface treatments, namely, dual acid ethcing that was performed using $\mathrm{H}_{2} \mathrm{SO}_{4}(98 \%)$ and $\mathrm{HCl}(35-38 \%)$, in sequence, for time durations ranging from $66,72,88$ hours for $\mathrm{H}_{2} \mathrm{SO}_{4}$ and 18, 24, 36, 48 hours for $\mathrm{HCl}$, and etching with $\mathrm{HF}$ acid for time duration ranging from 15 to 180 seconds, to create a surface topography on titanium that encorporates all the surface features in the aforementioned studies, and comparatively analyzed the resultant surface with the unetched titanium plates, using a surface profilometer. This was done to minimize the cost of surface treatment and to simplify the process.

The present study showed that precise acid selection, time, and the sequence of processing was the most crucial step in obtaining roughened titanium surface, which was in accordance with the study carried out by David Baker and co-workers, ${ }^{18}$ who determined that the dual etched surfaces using $\mathrm{H}_{2} \mathrm{SO}_{4}$ and $\mathrm{HCl}$ achieved higher roughness values and higher level of bone implant contact percentages. In a study by Buser et al, comparing influence 
of different surface characteristics on bone integration of titanium implants found highest extent of bone-implant interface in sandblasted (large grit) and acid etched $\mathrm{HCl}$ $+\mathrm{H}_{2} \mathrm{SO}_{4}$ group with mean values of 50 to $60 \%{ }^{19}$

Profilometer readings were used to determine the surface irregularities of unetched and etched titanium plates in this study. Generally, the surface characteristics of implant surfaces are compared using scanning electron microscopic examination or profilometer reading. Scanning electron microscopic examination studies are qualitative tests that reveal scratches produced on a surface. ${ }^{21}$ Profilometer results provide quantitative recording of surface irregularities. The profilometer is a device that uses a diamond stylus of precise dimensions to trace a fixed linear distance over the surface of the prepared sample. The profilometer produces a tracing and, using digital and analog hardware and software, also calculates the average surface roughness (Ra value) for the resultant tracing.

In this study, the following parameters for quantifying surface roughness were obtained for each plate:

- Roughness parameters (DIN EN ISO 4287:1998) ${ }^{22}$

- Ra-Arithmetic mean surface roughness: Arithmetical mean of the sums of all profile values in a given linear sample.

- Rq-Root mean square of the Ra values; it is a value characteristic of a continuously varying quantity.

- Rz-Average distance between the highest peak and lowest valley in each sampling length.

In the present study, the surface characterization of the titanium surfaces evaluated by surface profilometer showed different aspects in the topographies of the surfaces of titanium plates due to the different duration of acids used in the etching process. The average roughness value Ra obtained is $0.480 \mu \mathrm{m}$ for untreated surface and $3.65 \mu \mathrm{m}$ maximum for the T5 titanium plate after 72 hours of $\mathrm{H}_{2} \mathrm{SO}_{4}$ and 48 hours of $\mathrm{HCl}$ etching, which is about seven times the base value of the unetched surface. The average roughness values $\mathrm{Ra}$ for etched titanium plates ranging from 0.73 to 3.65 shows that acid etching was able to create micro-textured pits and waviness on the titanium surface, which was in accordance with the observations by Davies ${ }^{11}$ who also showed that acid etching of titanium creates a micro-textured surface (fine rough surface with micropits of 1-3 $\mu \mathrm{m}$ and larger pits of approximately $6-10 \mu \mathrm{m}$ ) that appears to enhance early endosseous integration and stability of the implant. This may be related to a change in surface roughness and/or chemical composition. $^{23}$

Another very important variable for determining the surface topography of titanium surface is Rz, which reveals the average distance between the highest peak and lowest valley in each sampling length. In this study, we found a wide range for the $\mathrm{Rz}$ values maximum in plate $\mathrm{T} 5(\mathrm{Rz}=24.87)$, which indicates that this surface had a very uneven waviness and distance between the crests and troughs was quite large, implying that the pits created after this sequence protocol were deepest compared with other plates. While comparing the surface of the etched titanium plates with the untetched titanium plates, we found that the surface roughness values for all plates were statistically significant except plate nos. T6, T8, T9, which belonged to the group II ( $\mathrm{H}_{2} \mathrm{SO}_{4}$ for 66 hours). Based on this observation, one can conclude that exposure of titanium surface to $\mathrm{H}_{2} \mathrm{SO}_{4}$ for 66 hours was not enough to significanlty alter the tianium surface from baseline.

The roughness values obtained after acid etching with HF acid did not show any significant improvement in surface characteristics compared with the unteched titanium plates. Moreover, the handling of HF was found to be cumbersome and caused time-dependent erosion of the titanium plates leading to severe loss in surface texture and weight at longer time durations above 60 seconds. These findings are in accordance with the results found by $\mathrm{A}$. Thirugnanam et al also found nonsignificant results and loss of an average of $14 \%$ weight after acid etching of titanium surface with HF acid alone. ${ }^{24}$ Thus from the findings of this study, we conclude that HF acid, used alone, was unsuitable at a concentration of $40 \%$, to be used for acid etching of titanium plates, although microroughness obtained by the same is similar to the semipolished unetched titanium plates and could be superimposed on macro roughness obtained by other means.

A study conducted to comparatively analyze the surface of four etched implants used the profile roughness measurements to characterize the surface of the four tested implants-DPS Frialit II, Osseotite, SLA-ITI, HaTi. The analyses showed that each implant surface displayed a distinct surface topography with $\mathrm{Ra}$ values ranging from $0.589 \mu \mathrm{m}$ of osseotite implant to $2.455 \mu \mathrm{m}$ of SLA-ITI implant, though all of them were found to be equally successful in osseointegration in clinical studies. $^{25}$ This observation implies that various acid etching techniques for obtaining surface roughness, though appear to be comparatively significant in in vitro studies, may not be superior clinically, and further biological, histomorphometric, and human trials are required to establish its effectiveness.

\section{CONCLUSION}

The specific dual acid etching technique using $\mathrm{H}_{2} \mathrm{SO}_{4}$ (98\%) followed by $\mathrm{HCl}(35-38 \%$ ) proposed in this experiment yields roughness parameters similar to the various implant surfaces available commercially when studied 
in vitro. Etching of titanum plates with $\mathrm{HF}$ acid was found to be cumbersome and hazardous in the proposed setting and did not yield any significant enhancement of surface roughness compared with machine-prepared unetched plates. The present study showed that by optimizing the parameters of acid etching a rough titanium surface can be obtained similar to the various implant surfaces available commercially. Thus, dual acid etching seems to be a simple technique to develop a titanium implant surface, though evaluation of the biological response to this surface is necessary.

\section{REFERENCES}

1. Brånemark PI. Osseointegration and its experimental background. J Prosthet Dent 1983 Sep;50(3):399-410.

2. Alberktsson T, Branemark PI, Hanson HA, Lindstorm J. Osseo integrated titanium implants. Requirements for ensuring a long lasting, direct bone to implant anchorage in man. Acta Orthop Scand 1981;52(2):155-170.

3. Cochran DL. A comparison of endosseous dental implant surfaces. J Periodontol 1999;70:12.

4. Lacefield WR. Materials characteristics of uncoated/ceramiccoated implant materials. Adv Dent Res 1997 Jun;13:21-26.

5. Simon Z, Watson PA. Biomimetic dental implants-new ways to enhance osseointegration. J Can Dent Assoc 2002 May;68(5):286-288.

6. Stanford CM. Surface modifications of dental implants. Aus Dent J 2008 Jun;53(Suppl 1):S26-S33.

7. Le Guehennec L, Soueidan A, Layrolle P, Amouriq Y. Surface treatments of titanium dental implants for rapid osseointegration. Dent Mater 2007 Jul;23(7):844-854.

8. Degidi M, Petrone G, Lezzi G. Bone contact around acid etched implants: a histological and histomorphometric evaluation of human-retrieved implants. J Oral Impalntol 2003;29(1):13-18.

9. Jungner $M$, Lundqvist $P$, Lundgren S. Oxidized titanium implants (Nobel Biocare TiUnite) compared with turned titanium implants (Nobel Biocare Mark III) with respect to failure in a $\mathrm{v}$ of consecutive patients treated with early functional loading and two stage protocol. Clin Oral Implants Res 2005;16(3):308-312.

10. Wennerberg A, Albrektsson T, Andersson B. Bone tissue response to commercially pure titanium implants blasted with fine and coarse particles of aluminium oxide. Int J Oral Maxillofac Implants 1996 Jan-Feb;11(1):38-45.

11. Davies JE. Mechanisms of endosseous integration. Int J Prosthodont 1998 Sep-Oct;11(5):391-401.

12. Lazzara R, Testori $\mathrm{T}$, Trisi $\mathrm{P}$, Porter $\mathrm{S}$. A human histologic analysis of osseotite and machined surface using implants with 2 opposing surfaces. Int J Periodontics Restorative Dent 1999 Apr;19(2):117-129.

13. Parekh RB, Shetty O, Tabassum R. Surface modifications for endosseous dental implants. Int J Oral Implantol Clin Res 2012;3(3):116-121.

14. Barier RF, Natiella JR, Meyer AE, Carter JM. Importance of implant surface preparation for biomaterials with different intrinsic properties. Tissue integration in oral and maxillofacial reconstruction. Steenberghe D, Albrektsson T, Brånemark.PI, editors. Amsterdam: Excerpta Medica; 1985. p. 13-40.

15. Lucchini J-P, Aurelle J-L, Therin M, Donath K, Becker W. A pilot study comparing screw-shaped implants. Surface analysis and histologic evaluation of bone healing. Clin Oral Implants Res 1996 Dec;7(4):397-404.

16. PredeckiP, Auslaender BA, StephanJE, Mooney VL, StanitskiC. Attachment of bone to threated implants by ingrowth and mechanical interlocking. J Biomed Mater Res 1972 Sep;6(5):401-412.

17. Coelho PG, Granjeiro JM, Romanos GE, Suzuki M, Silva NR, Cardaropoli G, Thompson VP, Lemons JE. Review basic research methods and current trends of dental implant surfaces. J Biomed Mater Res B Appl Biomater 2009 Feb;88(2): 579-596.

18. Baker D, London RM, Neal R. Rate of pull-out strength gain of dual-etched titanium implants: a comparative study in rabbits. Int J Oral Maxillofac Implants 1999 Sep-Oct;14(5):722-728.

19. BuserD,SchenkRK, SteinemannS, FiorelliniJP, Fox CH,StichH. Influence of surface characteristics on bone integration of titanium implants. A histomorphometric study in miniature pigs. J Biomed Mater Res 1991 Jul;25(7):889-902.

20. Juodzbalys G, Sapragoniene M, Wennerberg A, Baltrukonis T. Titanium dental implant surface micromorphology optimization. J Oral Implantol 2007;33(4):177-185.

21. Bandi S. Evaluation and comparison of mechanical and chemical surface modifications of commercial titanium for orthodontic implants. Ann Essen Dent 2012 Jul-Sep;4(3): 9-14.

22. Steven R. Jefferies, Wayne W. Barkmeier, John A. Gwinnett. Three composite finishing systems: a multisite in vitro evaluation. J Esthet Dent 1992 Nov-Dec;4(6):181-185.

23. Lazzara RJ, Testori T, Trisi P, Porter SS, Weinstein RL. A human histologic analysis of osseotite and machined surface using implants with 2 opposing surfaces. Int J Periodontics Restorative Dent 1999 Apr;19(2): 117-129.

24. Thirugnanam A, Sampath Kumar TS, Chakkingal U. Bioactivity enhancement of commercial pure titanium by chemical treatments. Trends Biomater Artif Organs 2009; 22(3):202-210.

25. Szmukler-Moncler S, Testori T, Bernard JP. Etched implants: a comparative surface analysis of four implant systems. J. Biomed Mater Res B Appl Biomater 2004 Apr 15;69(1):46-57 